\title{
Characterization of the Italian lake-types and identification of their reference sites using anthropogenic pressure factors
}

\author{
Elisa BURASCHI*, Franco SALERNO, Chiara MONGUZZI, Giulia BARBIERO ${ }^{1)}$ and Gianni TARTARI \\ CNR Istituto di Ricerca sulle Acque, Località Occhiate, 20047 Brugherio, Milano, Italy \\ CNR Istituto di Ricerca sulle Acque, Via Reno 1, Roma, Italy \\ *e-mail corresponding author: buraschi@irsa.rm.cnr.it
}

\begin{abstract}
The ultimate aim of the Water Framework Directive (WFD 00/60/EC) is the achievement of good water status for all waters by 2015. The WFD requires water bodies to be differentiated according to types determined using either System A or System B. Both systems are based on morphometric descriptors and the predominant composition of the geological substratum. Then, for each type, reference sites regarding their ecological status must be identified through the analysis of different elements, primarily by evaluating pressures and impacts on water bodies. This paper discusses the characterization of 190 Italian lake-types (selected on the basis of size, i.e. surface area $>0,5 \mathrm{~km}^{2}$ ) using both systems, and a method for determining their potential reference sites by analysing the pressure factors involved. The results show that System A is not suitable for Italian lakes; too high a number of types (36) emerges, and the distribution of the lakes into the various types is not homogeneous, making it difficult to identify reference sites. In contrast, the application of System B, including optional (i.e. conductivity and origin) as well as obligatory factors, makes it possible to group together the types and reduce their number. Thirteen different types, containing between 1 and 44 lakes, were identified using System $B$. The method developed to identify reference sites is based on the analysis of anthropogenic pressure. It was estimated from the equivalent population density (inhab. $\mathrm{km}^{-2}$ ) in topographic catchments and calculated using census data from ISTAT (Italian National Statistics Institute) (population, industry, animal husbandry). The equivalent population density, related to total phosphorus concentrations, enabled us to identify 5 potential reference sites, representative of 3 of the 13 types characterized (23\%). The method can be regarded as a preliminary approach to identifying reference sites, but must be refined through the addition of other pressure factors and other quality elements. Another approach to identifying reference sites is based on the relation between altitude (indirect index of anthropogenic pressures) and phosphorus concentration: high-altitude lakes (above $1000 \mathrm{~m}$ a.s.l.) have high or good quality status and can be regarded as potential reference sites. However, the development of a suitable method for identifying reference sites must consider the receptive capacity of a water body and its specificity; the identification of reference conditions must be specific for each type, and the analysis must be based on both spatial and temporal factors.
\end{abstract}

Key words: Water Framework Directive, lake-types, pressures, database, GIS

\section{INTRODUCTION}

Water quality assessment needs an approach that takes an inclusive view of the factors influencing its status, which can be identified as chemical, physical and anthropogenic pressures. The DPSIR (Drivings, Pressures, State, Impact, Responses) conceptual model sums up this methodological approach (EEA 2002). In Europe, modern water resource management has acknowledged the importance of these concepts, and has incorporated them into the Water Framework Directive (WFD 00/60/EC), which focuses primarily on ecological status and biological quality criteria, while the traditional chemical standards have become only supporting elements.

The Directive's ultimate aim is the achievement of a good water status for all waters by 2015 , by establishing a framework for community action in which aquatic environments are protected as part of a whole ecosystem, with lakes viewed in the context of their river basins.

This integrated approach is the innovative concept of the WFD: all levels of analysis and all disciplines (eco- nomic as well as scientific) must be considered (CIS 2003). The WFD sets other environmental objectives, which involve all the individual aspects of an aquatic ecosystem and require the restoration of water status, the prevention of its further deterioration, the reduction of polluting sources and finally the promotion of balanced and sustainable water uses (Art. 1, Art. 4).

To achieve these aims, each Member State of the European Community is required to undertake a series of key actions: to recognize the individual river basins lying within their national territory, to identify the main characteristics of river basins, especially the pressure factors and their impacts on water status (Art. 3, Art. 5), to draw up River Basin Management Plans (Art. 13) including artificial water bodies (AWB) and heavily modified water bodies (HMWB). Member States have to set up programmes to monitor biological, chemical and physico-chemical elements (Art. 8); they have to develop specific methods and intercalibrate them to define their ecological status (natural lakes) and their ecological potential (AWB and HMWB).

The first action required by the WFD is the identification of water bodies lying within each national terri- 
tory and their assignation to one of the surface water categories indicated (rivers, lakes, transitional waters or coastal waters). Secondly, each water body must be differentiated according to types determined using either System A or System B (Annex II, § 1.1). Both systems are based on morphometric descriptors and the predominant composition of geological substratum. System A is based on fixed categories of obligatory descriptors (ecoregions defined in map "A" in Annex XI: altitude, mean depth, lake area and geological substratum in the catchment; Annex II, $\S 1.2 .2$ ). System B is based on the same sequence of obligatory factors, but without fixing intervals, and also includes a set of optional factors, which can be used to draw up a better characterization than System A (Annex II, § 1.2.2).

The definition of the types is followed by identification of reference sites of ecological status, which must be defined through the following different elements: anthropogenic pressure factors and their impact on the water body, and hydromorphological, chemical and physico-chemical parameters. Finally, the essential element for determining the reference conditions (high quality ecological status) is an analysis of the structure of biological communities.

Meeting these requirements requires the collection of a large quantity of information on morphometric, hydrologic, anthropogenic, chemical, physico-chemical and biological features, and the development of suitable instruments such as databases and Geographic Information Systems (GIS) for data management (Nixon et al. 1998; Ryanzhin \& Straškraba 1999). Databases correlate, store and manage the collected information. GIS have evolved through the development of modern computerized resources: they add new contents and applicatory tools to traditional cartography and have become essential for analysing and managing territory (Sartori et al. 2001). Both of these instruments have a central role in the implementation of the WFD.

This paper presents a methodology for the classification into types of 190 Italian lakes, according to the Water Framework Directive. The main aims are:

- to classify lakes of a certain size (surface area $>0.5$

$\mathrm{km}^{2}$ ) into types and to identify the most appropriate classification system (System A or System B);

- to develop a method for identifying potential reference sites of ecological status, by analysing the anthropogenic pressure factors.

The ultimate aim is to contribute to solving at national level the scientific and technical problems involved in the implementation of the Directive.

\section{METHODS}

\subsection{Methodological approach to defining Italian lake types}

The methodological approach to classifying the Italian lakes used data collected in the LIMNO Project. Started in 1997, this project is jointly carried out by the
Institute of Water Research (IRSA-CNR) and by the Institute of Ecosystem Study (ISE-CNR). Its ultimate aim is to produce a tool for studying the main features (morphometrical, physical, chemical, biological and anthropogenic) of about 350 natural and artificial lakes distributed over the whole national territory. These lakes were selected on the basis of dimensional (surface area $>0.2 \mathrm{~km}^{2}$ ) and environmental criteria. LIMNO uses a database (LIMNO DataBase), implemented in Microsoft ${ }^{\circledR}$ Access ${ }^{\circledR} 2000$, linked with a GIS (GIS LIMNO), implemented by ESRI® ArcView ${ }^{\circledR}$ GIS 3.2.

\subsubsection{Morphometric factors}

Morphometry is an important direct tool for characterizing lacustrine environments, because it can be indirectly related to water quality (Barbanti 1978). Morphometric factors are essential for identifying water body types, as required by the WFD. In fact, specific quality elements can be used to analyse lake-types only after morphometric classification. The following morphometric parameters were used in the classification: lake area, altitude, maximum depth and mean depth.

The morphometric data are stored in the LIMNO DataBase, which includes most of the common morphometric parameters used in limnology (Hutchinson 1957; Tonolli 1969). These data have been collected both from scientific literature and direct cartographic measurements. The LIMNO DataBase contains a set of tables that collect several typologies of data, and other objects that facilitate data filing (forms) and database inquiry (queries). Tables are connected to each other by specific relationships.

Before including the data in the LIMNO DataBase, the sources of information were checked and the quality of the data verified; each parameter was compared with two reference sources (Tartari et al. 2002). In particular, data on natural lakes were compared with inventory values contained in the book "I laghi d'Italia" (Riccardi 1925), while data on reservoirs were compared with the values provided by the Italian Dam Register of the National Dams Service (Dipartimento per i Servizi Tecnici Nazionali).

Comparisons between different sources of morphometrical data showed high reliability (some are reported in table 1). In general the differences are less then $2 \%$. Only lake surface area and lake volume of AWB and HMWB are linear $(r>0.96 ; p<0.001)$, but differ by 9 and $16 \%$ respectively, due to the higher variability in these parameters.

As table 1 shows, the unreliabilities are reduced to a minimum, so that the sources of information may be regarded as reliable.

This data check made it possible to choose the reference values for each parameter. The lake type identification was applied to 190 lakes, selected by surface area $\left(>0.5 \mathrm{~km}^{2}\right)$ to characterize larger water bodies requiring classification (as indicated by System A; Annex II, $\S$ 1.2.2). 
Tab. 1. Linear regression comparison ( $\mathrm{N}=$ number of lakes; $a=$ slope; $b=$ intercept; $r$ $=$ correlation coefficient) between morphometric parameters and selected reference data.

\begin{tabular}{lcccccc}
\hline Parameter & Unit & Lakes & $\mathrm{N}$ & $a$ & $b$ & $r$ \\
\hline \multirow{2}{*}{ Lake's area } & \multirow{2}{*}{$\mathrm{km}^{2}$} & Natural & 51 & 0.988 & -0.1 & 0.994 \\
& & Artificial & 205 & 1.089 & -0.042 & 0.973 \\
Altitude & Natural & 71 & 0.997 & 0.682 & 0.999 \\
Maximum depth & $\mathrm{m}$ a.s.l. & Artificial & 271 & 0.999 & -0.357 & 0.999 \\
\multirow{2}{*}{ Volume } & $\mathrm{m}$ & Natural & 57 & 1.009 & 1.038 & 0.999 \\
& \multirow{2}{*}{$\mathrm{M} \mathrm{m}^{3}$} & Natural & 23 & 0.986 & -1.177 & 0.992 \\
& & Artificial & 342 & 1.158 & -0.121 & 0.958 \\
\hline
\end{tabular}

\subsubsection{Geological factors}

The characterization of lake types requires an analysis of catchment geology, to classify lakes in the following categories: prevalently siliceous, calcareous or organic (uncommon in Italy) (WFD, Annex II, § 1.2.2). This analysis was performed by GIS LIMNO, which is made up of two polygonal layers (representing the lakes and their catchments) determined on official Italian cartography (at the scale of $1: 25,000,1: 50,000$ or $1: 100,000)$, then georeferenced and digitised.

Catchment layers were overlaid on a georeferenced Italian geological map at the scale of 1:1,000,000 (Servizio Geologico, 1961) which made it possible to define the nature of their substratum. The georeferencing was done by an ArcView GIS ${ }^{\circledR} 3.2$ extension (Warp.avx). It calculates an algorithm of mathematical resampling (nearest neighbour method) that assigns real-world coordinates to each point of an image. This process requires at least 4 reference-points: first the software converts the image to a grid, then assigns coordinates to each cell of the grid (ESRI 1998). In this case the reference frame is UTM, E. D. 1950.

\subsubsection{Use of hydrochemical variables to validate the classification of geological types}

The georeferenced map made it possible to determine the geological category of each catchment. However, the scale was not often suitable for characterizing small basins. The same map classifies the geological formations only on a temporal basis (referring them to a precise geological Era or Epoch), so that it was sometimes difficult to determine the nature of the substratum.

This analysis was supported by the use of two hydrochemical variables: total alkalinity (TAlk, meq $\mathrm{l}^{-1}$ ) and conductivity (Cond, $\mu \mathrm{S} \mathrm{cm}^{-1} 20^{\circ} \mathrm{C}$ ), available for most of the lakes in the LIMNO DataBase. These parameters are connected to geochemical features. To find out the prevalent nature of the catchments, the discriminant limits of total alkalinity $\left(0.8 \mathrm{meq}^{-1}\right)$ and conductivity $\left(250 \mu \mathrm{S} \mathrm{cm} \mathrm{cm}^{-1} 20{ }^{\circ} \mathrm{C}\right)$ were determined using reference values for Lago Maggiore, which is characterized by a catchment where siliceous and calcareous rocks are equally distributed.
The classification of geological types was determined by the analysis of the substratum map, validated by the data on alkalinity and conductivity. Literature data were used in some difficult cases.

\subsubsection{Definition of the classification grid for System B}

System B "...must achieve at least the same degree of differentiation as would be achieved using System A. Accordingly, the surface water bodies within the river basin district shall be differentiated into types using the values for the obligatory descriptors and such optional descriptors, or combinations of descriptors, as are required to ensure that type specific biological reference conditions can be reliably derived..." (WFD, Annex II).

System B considers the same obligatory factors as System A; it differs in so far as it permits the use of additional factors, besides lacking the prescription of the descriptors' specific intervals. Each Member State can choose the most suitable system to characterize its water bodies, but it must obtain the same degree of differentiation: this is interpreted "...to mean that if System B is used, it should result in no greater degree of variability in type specific reference conditions than if System A had been used..." (CIS 2003).

In the case of Italian lakes, the obligatory factors used in the System B classificatory grid are reported in the following list:

- altitude;

- latitude; used to divide Italy into North and Central-

South-Islands;

- prevalent composition of geological substratum; the subdivision fixed by System A was kept, with the exclusion of organic typologies;

- maximum depth and lake area.

Longitudinal subdivisions were not applied: they were not useful for the classification because of the peculiar shape of the Italian Peninsula.

In addition to the obligatory factors, the following optional descriptors were included in the System B classification:

- conductivity ( $\mu \mathrm{S} \mathrm{cm}^{-1} 20{ }^{\circ} \mathrm{C}$ ): used to differentiate freshwaters from saline waters;

- mean depth, used to differentiate deep and shallow lakes; 
Tab. 2. Values of class boundaries for the descriptors used to classify the lakes-types. (*): Ca = calcareous; $\mathrm{Si}=$ siliceous

\begin{tabular}{|c|c|c|c|c|c|c|c|}
\hline \multirow{2}{*}{$\begin{array}{l}\text { Types } \\
\text { Definition }\end{array}$} & \multirow[b]{2}{*}{$\mathrm{N}$} & \multirow[t]{2}{*}{ Latitude } & \multirow{2}{*}{$\begin{array}{l}\text { Altitude } \\
\text { (m a.s.1.) }\end{array}$} & \multicolumn{2}{|c|}{ Depth } & \multirow{2}{*}{$\begin{array}{l}\text { Area } \\
\left(\mathrm{km}^{2}\right)\end{array}$} & \multirow[t]{2}{*}{ Geology $(*)$} \\
\hline & & & & $\max (\mathrm{m})$ & mean $(\mathrm{m})$ & & \\
\hline low altitude, calcareous, shallow, small & 1 & $>44^{\circ} 00^{\prime}$ & $<800$ & $<120$ & $<15$ & $<100$ & $\mathrm{Ca}$ \\
\hline low altitude, calcareous, deep, small & 2 & $>44^{\circ} 00^{\prime}$ & $<800$ & $<120$ & $>15$ & $<100$ & $\mathrm{Ca}$ \\
\hline low altitude, calcareous, very deep, large & 3 & $>44^{\circ} 00^{\prime}$ & $<800$ & $>120$ & \# & $>100$ & $\mathrm{Ca}$ \\
\hline low altitude, siliceous & 4 & $>44^{\circ} 00^{\prime}$ & $<800$ & $\#$ & \# & $\#$ & $\mathrm{Si}$ \\
\hline high altitude, calcareous & 5 & $>44^{\circ} 00^{\prime}$ & $>800$ & \# & \# & \# & $\mathrm{Ca}$ \\
\hline high altitude, siliceous & 6 & $>44^{\circ} 00^{\prime}$ & $>800$ & \# & \# & $\#$ & $\mathrm{Si}$ \\
\hline low altitude, calcareous, shallow & 7 & $<44^{\circ} 00^{\prime}$ & $<800$ & \# & $<15$ & \# & $\mathrm{Ca}$ \\
\hline low altitude, calcareous, deep & 8 & $<44^{\circ} 00^{\prime}$ & $<800$ & \# & $>15$ & \# & $\mathrm{Ca}$ \\
\hline low altitude, siliceous & 9 & $<44^{\circ} 00^{\prime}$ & $<800$ & \# & \# & \# & $\mathrm{Si}$ \\
\hline high altitude, calcareous & 10 & $<44^{\circ} 00^{\prime}$ & $<800$ & \# & \# & $\#$ & $\mathrm{Ca}$ \\
\hline high altitude, siliceous & 11 & $<44^{\circ} 00^{\prime}$ & $>800$ & $\#$ & \# & $\#$ & $\mathrm{Si}$ \\
\hline volcanic & 12 & \multicolumn{6}{|c|}{ volcanic origin } \\
\hline saline & 13 & \multicolumn{6}{|c|}{ Conductivity $>5000 \mu \mathrm{S} \mathrm{cm}^{-1} 20^{\circ} \mathrm{C}$} \\
\hline
\end{tabular}

\begin{tabular}{|c|c|c|c|c|c|c|c|c|c|c|c|}
\hline \multicolumn{12}{|c|}{ CONDUCTIVITY } \\
\hline \multicolumn{11}{|c|}{$<5000 \mu \mathrm{S} \mathrm{cm}^{-1} 20^{\circ} \mathrm{C}$} & \multirow{2}{*}{$\frac{\geq 5000 \mu \mathrm{S} \mathrm{cm}^{-1} 20^{\circ} \mathrm{C}}{\text { type } 13}$} \\
\hline & & & & & & & & & & & \\
\hline \multicolumn{11}{|c|}{ LATITUDE } & \\
\hline \multicolumn{5}{|c|}{$\geq 44^{\circ} 00^{\prime}$} & \multicolumn{6}{|c|}{$<44^{\circ} 00^{\prime}$} & \\
\hline \multicolumn{5}{|c|}{ NORTH } & \multicolumn{6}{|c|}{ CENTRAL-SOUTH-ISLE } & \\
\hline & & & & & \multicolumn{6}{|c|}{ LAKE'S ORIGIN } & \\
\hline & & & & & \multirow{2}{*}{\multicolumn{5}{|c|}{ Other origins }} & Volcanic origin & \\
\hline & & & & & & & & & & type 12 & \\
\hline \multicolumn{10}{|c|}{ ALTITUDE } & & \\
\hline \multicolumn{3}{|c|}{$<800$ m a.s.l. } & $\geq 800 \mathrm{~m}$ & 1.s.I. & \multicolumn{3}{|c|}{$<800$ m a.s.l. } & \multicolumn{2}{|c|}{$\geq 800 \mathrm{~m}$ a.s.l. } & & \\
\hline \multicolumn{10}{|c|}{ GEOLOGICAL SUBSTRATUM } & & \\
\hline \multicolumn{2}{|c|}{ Calcareous } & Siliceous & Calcareous & Siliceous & Calca & eous & Siliceous & Calcareous & Siliceous & & \\
\hline \multirow{2}{*}{\multicolumn{2}{|c|}{$\begin{array}{l}\text { MAXIMUM DEPTH } \\
\text { MEAN DEPTH }\end{array}$}} & type 4 & type 5 & type 6 & \multirow{2}{*}{\multicolumn{2}{|c|}{\begin{tabular}{c|c} 
MEAN DEPTH \\
\\
$<15 \mathrm{~m}$ & $\geq 15 \mathrm{~m}$ \\
\end{tabular}}} & type 9 & type 10 & type 11 & & \\
\hline & & & & & & & & & & & \\
\hline $\begin{array}{c}<120 \mathrm{~m} \\
<100 \mathrm{~km}^{2} \\
\end{array}$ & $\begin{array}{c}>120 \mathrm{~m} \\
\geq 100 \mathrm{~km}^{2} \\
\end{array}$ & & & & \multicolumn{2}{|c|}{\begin{tabular}{|l|l|} 
type 7 & type 8 \\
\end{tabular}} & & & & & \\
\hline \multirow{2}{*}{$\begin{array}{l}\text { MEAN DEPTH } \\
\begin{array}{c|c}<15 \mathrm{~m} & \geq 15 \mathrm{~m}\end{array}\end{array}$} & type 3 & & & & & & & & & & \\
\hline & & & & & & & & & & & \\
\hline \begin{tabular}{l|l} 
type 1 & type 2
\end{tabular} & & & & & & & & & & & \\
\hline
\end{tabular}

Fig. 1. System B's classification grid applied to 190 main Italian lakes.

- lakes of volcanic origin: highlights the peculiar features of the lakes of the Central Volcanic District of Italy (Latium).

System B requires the definition of class boundaries for both obligatory and optional descriptors. These boundaries are reported in table 2, together with the definition of 13 different lake types, characterized for the 190 natural lakes, artificial and heavily modified water bodies considered in this paper. Figure 1 shows the classification grid designed to identify the type for each lake: the first factor (conductivity) divides the water bodies into two groups that are subsequently split up by other parameters until homogeneous categories (types) are attained.

\subsection{Identification of reference lakes using anthropogenic parameters}

Anthropogenic parameters were determined by data on land use and population density, to identify potential reference sites free from pressure.

\subsubsection{Determination of fractions of classes of land use} and municipalities

To assess the anthropogenic pressure factors in each basin, the lake catchment layers were intersected with land use layer (CORINE-Land Cover) and municipality layer (ISTAT 1995). The classes of land use in each municipality were determined by thematic cartography 
Tab. 3. Morphometric features about the 190 selected lakes and categories of System A (WFD, Annex II, § 1.2.2.).

\begin{tabular}{|c|c|c|c|c|c|}
\hline \multirow{2}{*}{$\begin{array}{l}\text { System A's morphometric } \\
\text { descriptors }\end{array}$} & \multirow[t]{2}{*}{ Boundaries } & \multirow[t]{2}{*}{ Symbol } & \multirow[t]{2}{*}{ Description } & \multicolumn{2}{|c|}{ Frequency } \\
\hline & & & & Natural & Artificial \\
\hline \multirow{3}{*}{ Altitude (m a.s.l.) } & $<200 \mathrm{~m}$ a.s.l. & $\mathrm{H}$ & High altitude & 6 & 42 \\
\hline & $200-800 \mathrm{~m}$ a.s.1. & M & Middle altitude & 36 & 63 \\
\hline & >800 m a.s.1. & $\mathrm{L}$ & Low altitude & 13 & 30 \\
\hline \multirow{3}{*}{ Lake's mean depth (m) } & $<3 \mathrm{~m}$ & VSh & Very shallow & 4 & 0 \\
\hline & $3-15 \mathrm{~m}$ & $\mathrm{Sh}$ & Shallow & 22 & 52 \\
\hline & $>15 \mathrm{~m}$ & $\mathrm{D}$ & Deep & 29 & 83 \\
\hline \multirow{4}{*}{ Lake's area $\left(\mathrm{km}^{2}\right)$} & $0,5-1 \mathrm{~km}^{2}$ & VSm & Very small & 12 & 38 \\
\hline & $1-10 \mathrm{~km}^{2}$ & $\mathrm{Sm}$ & Small & 31 & 89 \\
\hline & $10-100 \mathrm{~km}^{2}$ & $\mathrm{La}$ & Large & 7 & 8 \\
\hline & $>100 \mathrm{~km}^{2}$ & VLa & Very large & 5 & 0 \\
\hline \multirow{2}{*}{ Geological substratum } & Calcareous & $\mathrm{Ca}$ & Calcareous substratum & \multicolumn{2}{|c|}{130} \\
\hline & Siliceous & $\mathrm{Si}$ & Siliceous substratum & \multicolumn{2}{|c|}{54} \\
\hline
\end{tabular}

of the CORINE-Land Cover Project (Bossard et al. 2000) at the scale of 1:100,000. CORINE-Land Cover is divided into three hierarchical levels describing land use typologies. This paper uses the first level, which consists of five classes describing the main land uses. Four new layers were identified for each basin, and for all of them the areas of each municipality and of each land cover class were computed by ArcView GIS ${ }^{\circledR} 3.2$.

This operation made it possible to calculate the fractions of each class of land use and of each municipality's population. The methodology was applied to 50 natural lakes with an area greater or equal to $0.5 \mathrm{~km}^{2}$.

\subsubsection{Equivalent population density}

Equivalent population density is a measure of anthropogenic pressure. It was compared with the concentrations of total phosphorus measured at the overturn. Phosphorus values were extracted from the LIMNO DataBase, and refer to the decade from 1990 to 1999.

The equivalent population density was estimated using two methods. In the first, the data were indiscriminately distributed over the area of the municipality, while in the second method the individual categories were related to their specific land uses (i.e. population to urban areas, industrial employers to industrial areas, etc.).

Pressure factor data were taken from the population and industry census taken by ISTAT in 1991, and from the 1990 animal husbandry census.

The intersections with the ISTAT layer made it possible to calculate the area of each municipality in the basins. By knowing the area of the whole surface, the percentage of each municipality's partial surface could be calculated. With the fractions obtained, the number of inhabitants, industrial employers and cattle could be assigned to each municipality and, by addition, to each catchment.

The total equivalent population was calculated as the sum of each individual category of anthropogenic pressure (number of inhabitants, number of industrial employers and number of cattle). The categories of industry and animal husbandry were standardized by unitary coefficients of phosphorus production (Barbiero 1991; Pagnotta \& Barbiero 2003) in order to determine their respective contribution, expressed as equivalent population; thus the number of industrial employers and head of cattle were converted into a number of inhabitants.

Then, to estimate the equivalent population density (expressed as inhab. $\mathrm{km}^{-2}$ ), the total equivalent population was referred to the emergent surface of catchment. The same data (population, industry and animal husbandry) were assigned to their specific land use fractions (determined by CORINE Land Cover). Finally, the equivalent population density (inhab. $\mathrm{km}^{-2}$ ) was estimated by the same coefficients. A comparison between the two approaches shows good agreement between them $(r=0.86)$, so they can be considered equivalent; consequently, the method of land use assignation was used in this study.

\section{RESULTS}

\subsection{Morphometric features of lakes}

The main morphometric features (altitude, lake area and mean depth) of the 190 lakes are summarized in table 3. Most of these lakes (36 natural and 63 reservoirs) lie at altitudes between 200 and $800 \mathrm{~m}$ a.s.l. Many of the reservoirs are situated above $800 \mathrm{~m}$ a.s.l., while only 6 natural lakes lie at high altitude. About $23 \%$ of the lakes (13 natural and 30 artificial) are situated below $200 \mathrm{~m}$ a.s.l.

Many of the artificial lakes have moderate dimensions: 89 of them have a surface area between $1 \mathrm{~km}^{2}$ and $10 \mathrm{~km}^{2}$, while 38 lakes are smaller than $1 \mathrm{~km}^{2}$. Only 8 reservoirs have a surface area greater than $10 \mathrm{~km}^{2}$, but none of them is larger than $100 \mathrm{~km}^{2}$. Most of the natural water bodies also have a surface area smaller than 10 $\mathrm{km}^{2}$, and few lakes have a surface area between $1 \mathrm{~km}^{2}$ and $10 \mathrm{~km}^{2}$. The 5 lakes with the greatest dimensions $\left(>100 \mathrm{~km}^{2}\right.$ ) are the 3 largest subalpine lakes (Como, Garda and Maggiore) and 2 lakes in Central Italy (Bolsena and Trasimeno). 
Of the natural water bodies, only 4 lakes are very shallow, characterized by mean depth values less than 3 $\mathrm{m}, 22$ lakes are shallow, with mean depth between $3 \mathrm{~m}$ and $15 \mathrm{~m}$, and 29 lakes are deeper than $15 \mathrm{~m}$. The mean depth of all the artificial lakes is greater than $3 \mathrm{~m}$.

\subsection{Catchment geology}

The substratum of the basins was defined by analysing the geological map in $82 \%$ of the study cases (i.e. 156 catchments). This attribution was verified in 114 cases through comparison with hydrochemical data (TAlk, Cond), while this was not possible for 6 water bodies. The prevalent substratum of the 36 remaining lakes was characterized only by reference to the geological map because there were no data for alkalinity or conductivity. In 34 case-studies the map determination was insufficient and confused, so the geological attribution was assigned either by hydrochemical variables ( 24 lakes) or literature information (10 lakes).

Figure 2 shows the combination of the three factors used: the different symbols are the substratum types, the $\mathrm{x}$-axis and the $\mathrm{y}$-axis indicate respectively values of alkalinity and conductivity. Generally speaking, low TAlk and Cond values were measured in the lakes with a prevalently siliceous catchment, while high values corresponded to a calcareous substratum.

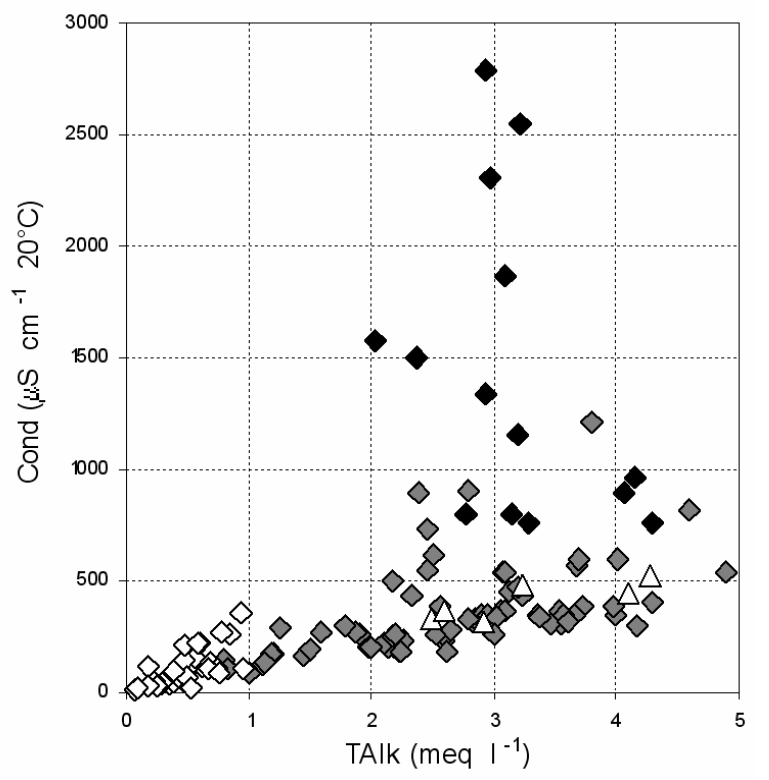

$\diamond$ Calcareous substratum

- Calcareous substratum (lakes of Sicily)

$\diamond$ Siliceous substratum

$\triangle$ Siliceous substratum (volcanic lakes)

Fig. 2. Characterization of geological substratum of the catchments by map analysis compared to the relationship between conductivity (Cond) and alkalinity (TAlk).

The only exceptions are the volcanic lakes of Latium, where high values of conductivity are due to the alkaline-potassic rocks that constitute the eruptive apparatus in which these lakes lie (Monguzzi 2002).

The lakes of Sicily are characterized by the highest values of conductivity $\left(>750 \mu \mathrm{S} \mathrm{cm}^{-1} 20^{\circ} \mathrm{C}\right)$ due to climatic factors and the geological history of the island (Bosellini et al. 1989), with the presence of a large quantity of easily soluble evaporitic rocks ("GessosoSolfifera Formation" and "Upper Gypsum" of Sicily).

Figure 3 shows the percentage of each geological type: the volcanic group represents 3\%, 130 lakes (69\%) have calcareous watersheds and the rest $(28 \%$, or 54 cases) lie on a siliceous substratum (in the Alps, in the Sila Tableland and in some areas of Sardinia).

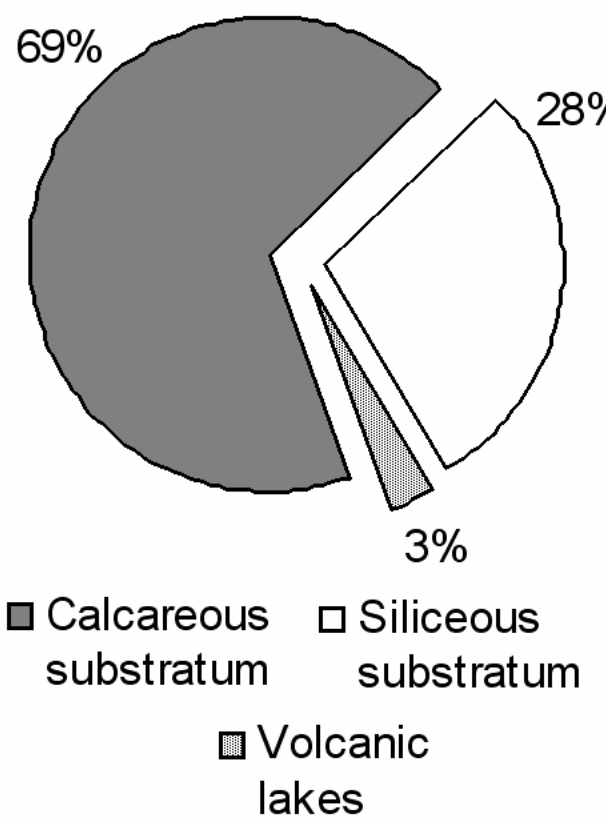

Fig. 3. Percentage of each typology of geological substratum of the catchments $(n=190)$.

\subsection{The main Italian lake-types}

This paragraph reports the results of the classification of Italian lake-types using both System A and System B.

\subsubsection{System A}

Italy belongs to two ecoregions: "Italy, Corsica and Malta" (ecoregion 3; WFD, Annex XI, map "A") and "Alps" (ecoregion 4; WFD, Annex XI, map "A"). The $1000 \mathrm{~m}$ a.s.l. level line was chosen to define the border between them (Illies, 1978): thus 156 lakes resulted distributed in ecoregion 3, and the remaining 34 in ecoregion 4.

The application of System A to the 190 selected lakes and reservoirs resulted in the identification of 36 different lakes types (Fig. 4), with 12 types including only one lake. Results by ecoregion show that 31 types belong to "Italy, Corsica and Malta", and 5 types to the Alps (see Table 3 for the explanation of type symbols). 


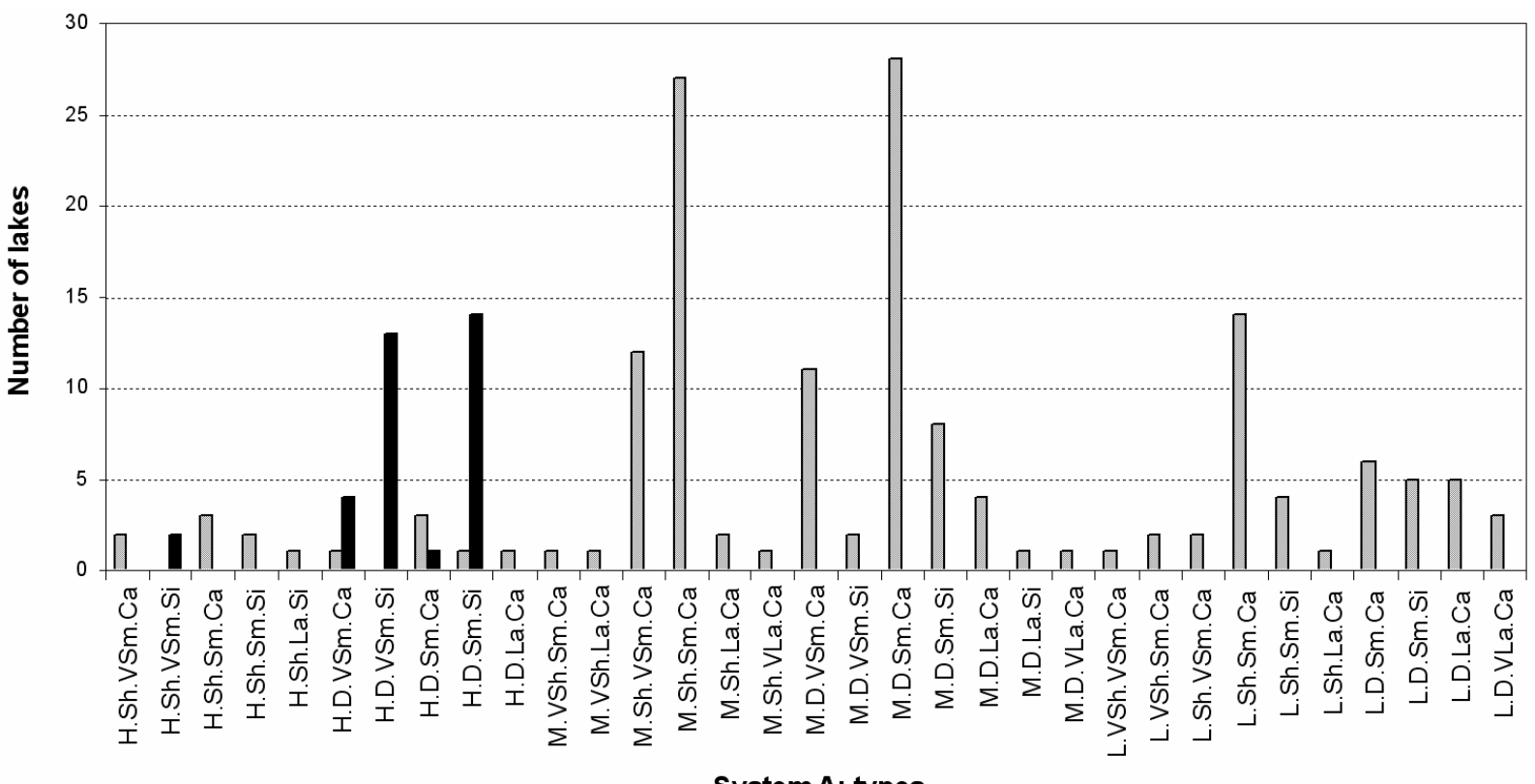

System A: types

૫ Ecoregion n.3:"ttaly, Corsica and Malta" (00/60/EC; Annex XI, map A)

-Ecoregion n.4:"Alps" (00/60/EC; Annex XI, map A)

Fig. 4. Results of the application of System A to 190 Italian lakes.

The wide variability of types is due to the peculiar shape of Italy.

\subsubsection{System B}

The application of System B, according to the methodology indicated above, resulted in the identification of 13 different types (Fig. 5) for the 190 selected lakes. Figure 5 shows the numeric distribution of the lakes into these 13 types; their definitions are reported in table 2 .

In greater detail, type 6 is the most representative of the Northern area (29 lakes) and includes high altitude lakes with siliceous catchments. Type 1 (18 lakes) and type 2 (19 lakes) represent respectively shallow and deep low altitude lakes lying on calcareous substratum. Type 7 and type 8 are the most representative of the Central-South regions and include respectively 44 and 29 water bodies, many of them artificial.

Type 9 and type 11 (low and high altitude lakes lying on siliceous substratum) include only reservoirs; type 8 and type 10 (low and high altitude lakes lying on calcareous substratum) comprise only one natural lake each.

\subsection{Identification of potential reference sites}

The method developed in this study for identifying reference sites is based on the relation found between the degree of anthropization of the territory and the total phosphorus concentration in the waters (Marchetti 1987). Total phosphorus can generally be considered the main limiting factor for algal growth, directly influencing a lake's trophic state. In this study, equivalent population density is taken to be a measurement of the anthropogenic pressure of the population of the catchment, industry and animal husbandry.



Fig. 5. Results of the application of System B to 190 Italian lakes. 
Tab. 4. Potential reference sites.

\begin{tabular}{lccc}
\hline Lake & TP & $\begin{array}{c}\text { Eq. population } \\
\text { density } \\
\left(\text { inhab. } \mathrm{km}^{-2}\right)\end{array}$ & Type \\
& $\left(\mu \mathrm{g} \mathrm{P}^{-1}\right)$ & 75 & Type 1 \\
Cavazzo & 4 & 165 & Type 4 \\
Mergozzo & 5 & 194 & Type 4 \\
Mezzola & 8 & 67 & Type 5 \\
Tovel & 4 & 47 & Type 5 \\
Molveno & 12 & & \\
\hline
\end{tabular}

Our study suggests that a lake needs to meet two conditions in order to be a potential reference site. The first is to have oligotrophic status, as defined by OECD (1982): the mean total phosphorus concentration must be lower than $10 \mu \mathrm{g} \mathrm{P}^{-1}$. The second condition is a low anthropogenic pressure on the lake catchment. The acceptable limit of equivalent density was estimated by the mean population density of sparsely populated Italian regions (ISTAT 1995), and must be lower than 200 inhab. $\mathrm{km}^{-2}$.

Through the combination of these two criteria we identified 5 potential reference sites (Tab. 4), representative of 3 of the 13 types characterized. An exception was Lake Molveno, with a P concentration of $12 \mu \mathrm{g} \mathrm{P}^{-}$ ${ }^{1}$ : this lake qualifies as a reference site because its $\mathrm{P}$ value makes it very close to oligotrophic conditions and anthropogenic pressure in the catchment is very low (47 inhab. $\mathrm{km}^{-2}$ ).

\section{DISCUSSION}

\subsection{Types of Italian lakes}

An analysis of the results of the classification of lake types shows that System A is not suitable for the Italian situation. The number of types emerging is too high (36 types in a sample of 190 lakes), making it almost impossible to identify reference sites for every type; moreover, a type which includes only one lake is meaningless, because it becomes a reference-site by itself (Fig. 4). The European Commission also recommends reducing the number of types, in line with the implementation of the WFD (CIS 2003).

Besides, the distribution of lakes in the types found through System A is not homogeneous: the morphometric classes imposed by the WFD are too rigid. In fact, similar lakes are not grouped together, because the WFD parameters all have the same weight. For example, lakes Mantova di Mezzo and Mantova Inferiore (type L. Sm. VSh. Ca.) are distinguished from Lake Mantova Superiore (type L. Sm. Sh. Ca.) only by mean depth, but in this case the parameter cannot be a discriminant, because the values are very similar $(<3 \mathrm{~m}$ in the first and the second cases and about $4 \mathrm{~m}$ in the third). The subdivision into ecoregions is another factor giving rise to some contradictions, because it does not take account of the geographic location of the lakes. For example, lakes in Lombardy and Sicily are classified as the same M. La. Sh. Ca. type (respectively Lake Varese and Ogliastro Reservoir), and some lakes in Lombardy, Sardinia and Latium are assigned to the same M. La. D. Ca. type (respectively lakes Lugano and Idro, Mulargia Reservoir and Lake Vico). Geographic position influences the ecological features of lakes, so that reference conditions may be wrongly defined if the geographic attribution is incorrect. The case of Lake Lugano demonstrates how System A does not allow subalpine lakes with the same morphological features and a common origin to be grouped together (Bini et al. 1978). A factor should also be introduced into both systems to distinguish the origin of the volcanic lakes, which in the panorama of Italian lakes constitute a unique group with highly distinctive features.

These observations make it clear that System B is the method to be applied to the classification of Italian lakes. The introduction of optional factors and changes in the obligatory factors highlight the different values of the parameters and make it possible to reconstruct the real morphological and geographical similarities. Applying System B results in a smaller number of types (Fig. 5) and larger groups of lakes, which makes it easier to select reference sites.

The classification systems were applied to both natural lakes and reservoirs, with the result that some types, such as type 9, comprise only artificial lakes. These environments can be subject to unnatural water level fluctuations, which determine changes in morphometrical features and the thermal regime and can ultimately cause alterations in the structure of biological communities. It can be very difficult to establish reference conditions for these lakes, so that appropriate methods for studying them must be devised. In the Mediterranean region of Italy, in particular, it might be necessary to divide AWB and HMWB from natural lakes. In many cases Mediterranean reservoirs suffer such a marked summer dewatering as to cause an early breakdown of the thermocline (Naselli-Flores et al. 2003), which affects the physical, chemical and biological structure of the ecosystem. From this point of view, water bodies could be divided into those "maintaining summer stratification" and those "not-maintaining summer stratification". To restrict the number of types, it could also be useful to create sub-types. Another problem is "insularity", which, together with the lack of a welldeveloped river network and the Mediterranean climate, tends to enhance the temporary pattern of the reservoirs' inflow and outflow. This pattern strongly influences the 
annual variability of conductivity and alkalinity (Naselli-Flores 2003), and compromises the use of some hydraulic indices (such as renewal time) in classifying the lakes.

\subsection{The approach adopted for identifying reference sites}

The approach described in this paper for identifying reference sites can be a starting point for identifying lakes with high ecological status. However, very few potential reference sites, representative of only 3 types of the 13 characterized, could be identified with this method (Tab. 3). Besides, the two lakes Tovel and Mezzola cannot be used as reference sites for their respective types. While Lake Tovel is indeed characterized by low concentrations of total phosphorus $\left(4 \mu \mathrm{g} \mathrm{P} \mathrm{l}^{-1}\right)$ and by very low pressure factors, it presents incipient meromictic conditions. The hydrological regime of Lake Mezzola is transitional between lentic and lotic status, its renewal time is very short ( 0.2 years), and the lake undergoes the periodic intrusion of water from Lake Como.

The approach used, based only on two elements (equivalent population density and total phosphorus concentration), could be improved by including the analysis of other pressure factors (agriculture) and the introduction of other variables, such as nitrogen concentration in waters. Another limitation derives from considering anthropogenic pressure as an absolute parameter, instead of relating it to the receptive capacity of the water bodies; thus, the limit value determined (200 inhab. $\mathrm{km}^{-2}$ ), which shows the status of "absence" or "reduction" of anthropization, cannot be suitable for describing all cases.

The evaluation of anthropogenic pressure must be specific for each lake. Considering that each environment reacts differently to pressures, according to its hydromorphological, physical and geographic features, a critical level must be defined beyond which the lake is not able to support the impact. The approach would be similar to Vollenweider's model (Vollenweider 1976), in which the polluting load is correlated to morphometric and hydrologic parameters (mean depth and renewal time, respectively).

When the method is applied to a restricted number of lakes, the great difficulty is to find reference sites for each type. The first solution to this problem is to extend the classification to smaller water bodies (with an area between $0.2 \mathrm{~km}^{2}$ and $0.5 \mathrm{~km}^{2}$ ).

Altitude is another important morphometric factor that can be regarded as an indirect index of pressure. The graph in figure 6 illustrates the relationship between altitude and phosphorus concentration (index of trophic status). Its trend confirms the hypothesis that highaltitude lakes have lower or null anthropogenic pressure (expressed as phosphorus load), so that these environments have high or good quality status. This relationship is especially clear in the case of lakes lying above $1000 \mathrm{~m}$ a.s.l., but some low-altitude lakes can also be considered as potential reference sites, as shown in figure 6 , because of their good water-quality conditions.

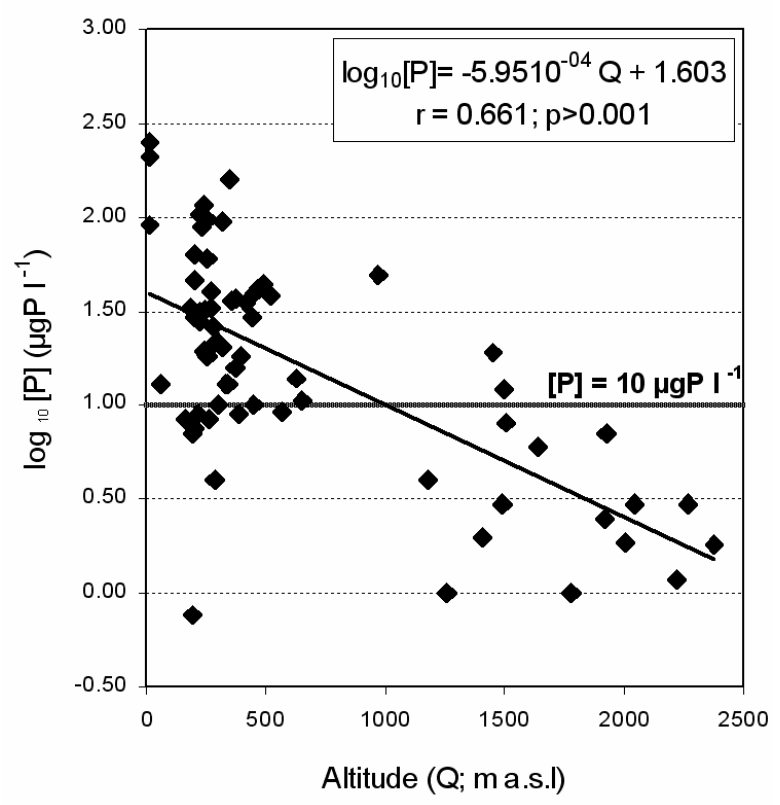

Fig. 6. Relationship between lake altitude ( $\mathrm{m}$ a.s.1.) and phosphorus concentration ( $\mu \mathrm{g} \mathrm{P}{ }^{-1}, \log$ transformed).

Figure 6 confirms indirectly that the application of the method to small lakes (with surface $<0.2 \mathrm{~km}^{2}$ ) can help in identifying reference sites. Using this approach (altitude versus total phosphorus), the number of reference sites can be increased, with the inclusion of some environments that were excluded with the previous method. For example, lakes Bolsena and Bracciano, representative of the volcanic lake type (type 12), were previously excluded because the population density is higher than 200 inhab. $\mathrm{km}^{-2}$.

Other problems are highlighted through this approach. Although most high-altitude lakes might be regarded as potential reference sites, in so far as they are present examples of environments that have in the past been subjected to low anthropogenic pressures, and in some cases constitute good examples of pristine status, they are not in fact suitable as references because altitude has a major influence on the structure of biological communities and the ecological status of lakes. It is especially difficult to identify reference sites for lowaltitude lakes and for those of Central-South Italy, where many lakes are artificial.

In identifying reference sites, the approach to be followed must be based on both spatial and temporal factors. In the first case (spatial approach), one or more water bodies may have features that make them suitable as references for the other lakes belonging to the same type. This is not feasible in some situations; for exam- 
ple, there are no conditions which can define the reference when the pressures are too high or when the (biological, hydromorphological or chemical) quality is too poor. In these cases, reconstruction of the original conditions (referring in particular to a period when the anthropogenic pressure was low) is essential and is based on either historical data or paleolimnologic studies (CIS 2003). To satisfy the diverse requirements of the WFD and identify reference sites, we need more information on morphological and qualitative features, especially those relating to biology.

\section{CONCLUSIONS}

The development of scientific bases for implementing the WFD is a difficult task. The new approach to the definition of water quality status - from a biological rather than a chemical standpoint - presents a stimulating challenge to European scientists, and also offers an excellent opportunity to look at water quality management from a "holistic" angle.

The classification of lake types and the identification of reference sites (the first two phases of the implementation of the WFD) are improving our knowledge of the characteristics of these environments, in particular as regards their hydrobiology. However, the main obstacle to implementing the WFD is the lack of specialists in the ecology of phytoplankton, macrophytes, fishes and benthos, paleolimnology, and also GIS experts in the evaluation of anthropogenic factors. The achievement of "good status" for water bodies will come about only through a general growth in the number of specialists involved and also through a significant improvement in limnological science.

\section{REFERENCES}

Barbanti, L. 1978. Parametri fisici nella modellistica del fenomeno dell'eutrofizzazione. Atti Convegno "Eutrofizzazione in Italia". CNR, Programma finalizzato "Promozione della qualità dell'ambiente". AC/2/48-1978: 45-70.

Barbiero, G., G. Carone, G. Cicioni, A. Puddu \& F.M. Spaziani. 1991. Valutazione dei carichi inquinanti potenziali per i principali bacini idrografici italiani: Adige, Arno, Po e Tevere. Quaderni Istituto Ricerca Sulle Acque, 90: 233 pp.

Bini, A., M.B. Cita \& M. Gaetani. 1978. Southern Alpine lakes - Hypothesis of an erosional origin related to the Messinian entrenchment. Marine Geology, 27: 271-288.

Bosellini, A., E. Mutti \& F. Ricci Lucchi. 1989. Rocce e successioni sedimentarie. UTET: $395 \mathrm{pp}$.

Bossard, M., J. Feranec \& J. Otahel. 2000. CORINE Land Cover Technical Guide. Addendum 2000. European Environment Agency. Technical Report, 40: 105 pp.
CIS. 2003. Guidance on establishing reference conditions and ecological status class boundaries for inland surface waters. Reference conditions for inland surface waters (REFCOND). Final version, 30 April 2003: 86 pp.

Directive of the European Parliament and of the Council 23 October 2000 n. 60. Framework for Community action in the field of water policy. Official Journal European Communities n. 327, 22/12/2000. 72 pp.

ESRI. 1998. Working with the ArcView Spatial Analyst. http://org.eea.eu.int/documents/brochure2002/approach.ht $\mathrm{ml}$

Hutchinson, G.E. 1957. A Treatise on Limnology. Geography, Physics and Chemistry. 1. John Wiley \& Sons: $137 \mathrm{pp}$.

Illies, J. 1978. Limnofauna Europaea. Gustav Fischer Verlag, Stuttgard: $532 \mathrm{pp}$.

Istituto Nazionale di Statistica. 1995. Le Regioni in cifre. ISTAT, Roma: 178 pp.

Marchetti, R. 1987. L'eutrofizzazione: un processo degenerativo delle acque. Collana Scientifica Franco Angeli, Milano: 319 pp.

Monguzzi, C. 2002. Peculiarità e analogie dei laghi dell'Italia Centro-Meridionale. Tesi di Laurea. Università degli Studi, Milano-Bicocca: $173 \mathrm{pp}$.

Naselli-Flores, L. 2003. Man-made lakes in the Mediterranean semi-arid climate: the strange case of Dr Deep Lake and Mr Shallow Lake. Hydrobiologia, 506/509: 13-21.

Naselli-Flores, L., R. Barone \& R. Mosello. 2003. Eutrophication control by lime addition: a preliminary approach in Sicilian reservoirs. Hydrobiologia, 504: 297-303.

Nixon, S., J. Grath \& J. Bogestrand. 1998. The European Environment Agency's monitoring and information network for inland waters resources. Technical guidelines for implementation. ETC/IW Ref: PO31/98/1. European Environment Agency. Technical Report, 7: 51 pp.

O.E.C.D. 1982. Eutrophication of waters. Monitoring, assessment and control. O.E.C.D., Paris: 164 pp.

Pagnotta, R. \& G. Barbiero. 2003. Stima dei carichi inquinanti nell'ambiente marino-costiero. Ann. Ist. Sup. Sanità, 39: 310.

Riccardi, R. 1925. I laghi d'Italia. Boll. R. Soc. Geogr. Ital., 2: $1-84$.

Ryanzhin, S.V. \& M. Straškraba. 1999. Geographical Information System of the world lakes (GIS WORLDLAKE) for limnological studies. SILnews, 27: $10 \mathrm{pp}$.

Sartori, F. 2001. Per una cartografia tematica lombarda. Metodologie di raccolta, elaborazione e rappresentazione di dati ambientali territoriali. Fondazione Lombardia per l'Ambiente-Università Studi Pavia: 578 pp.

Servizio Geologico Italiano. 1961. Carta geologica d'Italia. Scala 1:1,000,000. Ministero dell'Industria e del Commercio.

Tartari, G., E. Buraschi, C. Monguzzi, D. Copetti, L. Previtali, F. Salerno, A. Marchetto, G. Barbiero \& S. Tatti. 2002. Database dei corpi lacustri italiani significativi secondo $i$ criteri dei D.lgs 152/99 e 258/00. Rapporto finale IRSAANPA: $112 \mathrm{pp}$.

Tonolli, V. 1969. Introduzione allo studio della limnologia. Ecologia e biologia delle acque dolci. Istituto Italiano Idrobiologia, Pallanza-Verbania: $387 \mathrm{pp}$.

Vollenweider, R.A. 1976. Advances in defining critical loading levels for phosphorus in lake eutrophication. Mem. Ist. ital. Idrobiol., 33: 53-83. 